\title{
A Study to Assess the Knowledge on Swine Flu among Staff Nurses in Selected Hospital, Chennai
}

\author{
V. Hemavathy ${ }^{1}$, Girijabhaskaran ${ }^{2}$, Janailin Nongphud ${ }^{3}$ \\ Principal and Professor, Department of Mental Health Nursing, Sree Balaji College of Nursing, Bharath University Tamil Nadu, India \\ ${ }^{2}$ Professor, Dept of Medical Surgical Nursing, Sree Balaji College of Nursing, Bharath University Tamil Nadu, India \\ ${ }^{3}$ M.Sc Nursing, Dept of Medical Surgical Nursing, Sree Balaji College of Nursing, Bharath university Tamil Nadu, India
}

\begin{abstract}
Swine flu has been one of the most infectious diseases with its dramatic global pandemic spread. Since its emergence nursing personnel are required to have an understanding regarding the disease condition. A descriptive study, therefore, was undertaken to assess the knowledge of swine flu among staff nurses in selected hospital, Chennai. The study samples consisted of 30 staff nurses who are working in various units and were selected using purposive sampling technique. In order to assess their knowledge a self structured questionnaire was developed. Self-made scoring system was used to categorize the participants as whether they have adequate knowledge, moderately adequate knowledge or inadequate knowledge on swine flu. Results revealed that 6(20\%) of staff nurses had adequate knowledge, 21(70\%) of staff nurses had moderately adequate knowledge and 3(10\%) of staff nurses had inadequate knowledge about swine flu. Based on the results majority of the staff nurses had moderately adequate knowledge, it is therefore recommended that the nurses needs to upgrade their knowledge regarding swine flu as they play a vital role in educating the public about swine flu and caring for a swine flu client. Staff nurses should therefore be encouraged to update their knowledge through continuing education.
\end{abstract}

Keywords: Knowledge, swine flu, nurses, hospital, education.

\section{Introduction}

Swine flu is a respiratory disease, highly contagious, that regularly causes outbreaks of influenza in pigs. Swine influenza virus was first isolated from pigs in 1930 in the U.S. and has been recognized by pork producers and veterinarians to cause infections in pigs worldwide. On April 2009 in Mexico, the first case of novel influenza was announced. It is known to be rapidly spreading and poses a pandemic threat that, on 11 June, the World Health Organisation declared a global flu pandemic. In humans the pandemic spread is mainly due to the type A influenza (H1N1) virus and does not spread outside the respiratory tract.

Influenza type A (H1N1) virus ("swine flu") will not be going away any time soon, health officials say, and healthcare providers, including nurses, should prepare themselves not only for patients with the illness, but also for questions and concerns from the public, and requests to help state and local health departments identify potential new cases and also protecting themselves so as to perform their work effectively. The present study was conducted in order to assess the knowledge of swine flu among staff nurses in selected hospital, Chennai, with the main perspective of determining their knowledge regarding swine flu and put into service any implementation programme.

\section{Material and Method}

A descriptive study has been employed in this study to assess the knowledge of swine flu among staff nurses. The study was conducted in selected hospital, Chennai. A total of 30 staff nurses working in various units participated in the study. A self designed self structured questionnaire was developed to assess their knowledge. There were 30 multiple choice questions on definition, etiology, incubation period, clinical manifestations, warning signs, high risk group, diagnosis, treatment and control of swine flu. The data was collected by delivering the question sample to the participants and then collected after 1 hour. Each correct answer was given a score of "one" and wrong answer was given a score of "zero". . Self-made scoring system was used to categorize the participants as whether they have adequate knowledge, moderately adequate knowledge or inadequate knowledge on swine flu.

\begin{tabular}{|c|c|c|}
\hline S. No & Level of Knowledge & Percentage \\
\hline 1 & Adequate & $>75 \%$ \\
\hline 2 & Moderately adequate & $51-75 \%$ \\
\hline 3 & Inadequate & $<50 \%$ \\
\hline
\end{tabular}

The score was interpreted as follows:

\section{Results}

The findings of the study are discussed in terms of objective and hypothesis of the study.

\section{Sample Characteristics}

Most of the subjects (50\%) were in the age group of 21-25 years and minimum numbers of subjects $(3 \%)$ were found in the age group of 36-40 years.

$\square$ Most of the subjects were female $80 \%$ and male $20 \%$.

$\square$ With regard to professional qualification most of the subjects were GNM $53.3 \%$, B.Sc with $36.7 \%$ and the minimum subjects were the post basic covering only $10 \%$.

$\square$ Most of the subjects $36.7 \%$ had 5 years and above experiences. $23.3 \%$ had 3-4 years experience, and minimum $20 \%$ had 2 years or less experience. 


\section{International Journal of Science and Research (IJSR) \\ ISSN (Online): 2319-7064 \\ Index Copernicus Value (2013): 6.14 | Impact Factor (2014): 5.611}

$\square$ With regard to area of working most of the subjects $60 \%$ were from the ward area, $23.3 \%$ were from the ICU area and the minimum of subjects $16.7 \%$ were from the dialysis unit.

Most of the subjects $40 \%$ got information from the mass media which may be due to easy accessibility, 33.3\% got information from their colleagues which may be due to comfort approach, $16.7 \%$ got information from their supervisors and only $10 \%$ from the doctors.

The objective was to assess the level knowledge on swine flu among staff nurses: The frequency and percentage distribution of level of knowledge on swine flu among nurses reveal that $6(20 \%)$ of staff nurses had adequate knowledge, $21(70 \%)$ of staff nurses had moderately adequate knowledge and $3(10 \%)$ of staff nurses had inadequate knowledge about swine flu.

Table 1: Level of knowledge among staff nurses

\begin{tabular}{|c|c|c|}
\hline Knowledge level\% & No $(n=30)$ & Percentage \% \\
\hline Adequate $(75-100 \%)$ & 6 & $20 \%$ \\
\hline Moderate Adequate $(51-75 \%)$ & 21 & $70 \%$ \\
\hline Inadequate $(<50 \%)$ & 3 & $10 \%$ \\
\hline
\end{tabular}

Table 1 shows that $6(20 \%)$ of staff nurses had adequate knowledge, $21(70 \%)$ of staff nurses had moderate adequate knowledge and $3(10 \%)$ of staff nurses had inadequate knowledge about swine flu.

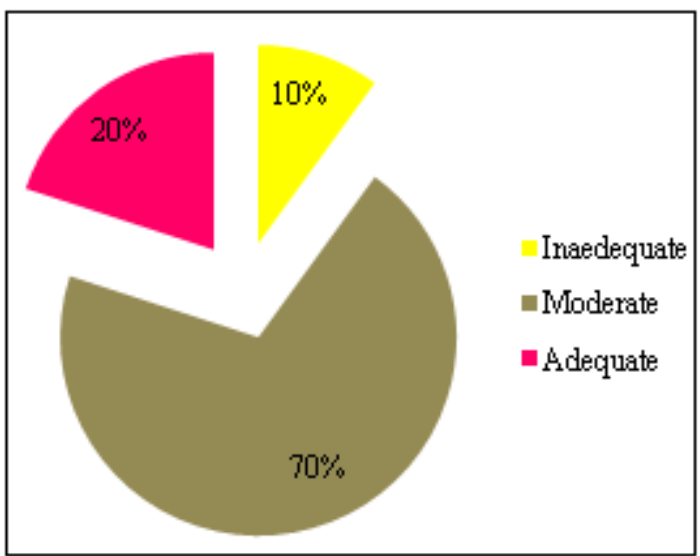

Figure 1: Percentage distribution on level of knowledge among staff nurses on swine flu

\section{Discussion and Conclusion}

The participants involved in this study were assessed for the knowledge on swine flu. The frequency and percentage distribution of level of knowledge on swine flu among staff nurses reveal that $6(20 \%)$ of staff nurses had adequate knowledge, $21(70 \%)$ of staff nurses had moderately adequate knowledge and $3(10 \%)$ of staff nurses had inadequate knowledge about swine flu. Sample characteristics of the study reveals that only $6(20 \%)$ had adequate knowledge on swine flu which throws light on the need for arrangement of educational sessions. Staff nurses needs to upgrade their knowledge regarding swine flu as they play a vital role in educating the public about swine flu and caring for a swine flu client. Also from the findings, it reveals that $3(10 \%)$ had inadequate knowledge, staff nurses should therefore be encouraged to update their knowledge through continuing education as nurses plays an important role in imparting knowledge and creating awareness about swine flu to their patients and the public as well as protecting oneself from infection.

\section{Reference}

\section{Book References:}

[1] Brunner \& Suddarth 's, “ Textbook of Medical Surgical Nursing" Volume 2, Eleventh edition, Wolters Kluwer, Lipinncott Williams \& Wilkins, Philadelphia, 2009: 2488-2489.

[2] K. Park, "Text Book of Preventive and Social Medicine" $17^{\text {th }}$ Edition ,Banarsidas Bhanot Publishers ,Jabalpur, 2002: 124-126.

[3] D.Peter Drotman, “ Emerging Infectious Disease", Volume 21, 2015: 251-258

[4] Hoeprich DP, “ Infectious Diseases, A modern Treatise of infectious processes", 3rd

[5] Edition, Harper \& Row Publishers, Philadelphia; 1983: 323-328.

[6] Mandell G L, Douglas RG, Bennett EJ. "Principles and practice of infectious diseases" 3rd edition, Churchill Livingstone, New York; 1990:1306-1325

[7] WHO "Combating Emerging Infectious Diseases in the South-East Asia Region” New Delhi; 2005:1-35.

\section{Journal References}

[8] Alexander Masting , et.al, (2011) "A study on the prevalence and risk factor of swine influenza virus infection in the English pig population", Feb 11.

[9] Abdi D. Osman, et.al, "Reasons for and barriers to influenza vaccination among healthcare workers in an Australian emergency department" Australian Journal of Advance Nursing Volume 27 Number 3,Pp no :38-43

[10] Data SS, Kuppuraman D, Boratne AV, Abraham SB, Singh Z (2011)“'Knowledge Attitude And Practice Regarding Swine Flu among Para medical workers in a tertiary care Hospital in Pondicherry" Journal of Communicable Disease Mar;43(1):1-9.

[11] Holly Seale; Julie Leask; C. Raina MacIntyre (2010) “ Attitudes Amongst Australian Hospital Healthcare Workers Towards Seasonal Influenza and Vaccination" Influenza and other Respiratory Viruses" Volume 4, Issue 1, Pp no: 41-46

[12] Jing Zhang, Alison E. While and Ian J. Norman (2010), "Knowledge and attitudes regarding influenza vaccination among nurses: A research review", August 28(44):7207-14

[13] La Torre G, Di Thiene D, Cadeddu C, Ricciardi W, Boccia A (2009) "Behaviours regarding Preventive measures against pandemic H1N1 influenza among Italian healthcare Workers" Volume 14, Issue 49, 10 December

\section{Net References}

[14] http://www.medicinenet.com

[15] http://www.cdc.gov/swineflu 